\title{
Research
}

\section{Role of attitudes and intentions in predicting adherence to oral diabetes medications}

\author{
Emmanuel K Fai ${ }^{1}$, Cheryl Anderson ${ }^{2}$ and Victor Ferreros ${ }^{2}$ \\ ${ }^{1}$ University of Maryland Medical Center Midtown Campus, Baltimore, Maryland, USA \\ ${ }^{2}$ Walden University, Minneapolis, Minnesota, USA
}

\section{Endocrine CONNECTIONS}

\author{
Correspondence \\ should be addressed \\ to E K Fai \\ Email \\ efai@umm.edu
}

\begin{abstract}
The purpose of this quantitative study was to investigate the extent to which patient attitudes and intentions predict adherence to the use of oral antihyperglycemic regimens in African Americans. This cross-sectional study of 115 participants used correlation analysis to establish relationships among patient attitudes, intentions and adherence. Data analyses showed significant correlations between the variables. Multiple regression analysis was used to establish predictions between the variables. A prediction model containing attitudes, subjective norms and perceived behavioral control (PBC) explained $37 \%$ of the variance to behavioral intention. Intentions accounted for $8.5 \%$ of the variance to adherence. Attitudes predicted behavioral intentions. The findings support the theory of planned behavior model and identify important correlations between attitudes, intentions and behaviors. In addition, the results underscore the need for promoting positive attitudes and positive intentions in effective adherence to the use of oral antihyperglycemic regimens. Achieving adequate adherence through behavioral counseling can effect positive social change by reducing the mortality and morbidity that are associated with inadequate adherence to the use of oral diabetic agents.
\end{abstract}

\author{
Key Words \\ - adult diabetes \\ - adherence \\ - oral antihyperglycemic \\ - African Americans
}

\section{Introduction}

Individual patient attitudes and intentions can influence adherence to the use of medical therapies. 'Adherence to the use of medical therapy' has been defined as the level of participation expected of an individual who has agreed to a prescribed treatment regimen (1). It is essential for patients with chronic medical conditions to adhere to prescribed regimens. Lack of an adequate adherence to the use of medical therapy can aggravate the disease course, and consequently, a low response to appropriate medical therapies (2). Researchers have estimated the percentage of nonadherence to the use of medical therapies in chronic medical conditions to be approximately 30-50\% of patients $(3,4)$. Improving adherence to therapies of chronic medical conditions is an essential strategy in combating chronic diseases.
Adequate adherence to the use of medical therapies is likely to minimize, delay or eliminate the morbidity and mortalities associated with chronic diseases $(5,6)$. Type 2 diabetes mellitus is a common chronic disease. Adherence to needed drug regimens is important for individuals with type 2 diabetes. Inadequate adherence to the use of medical therapies results in poor glycemic control and thus increase the rate of mortality and morbidity $(7,8)$ and high hemoglobin A1C (HbA1C) values $(6,9)$. To minimize the consequences of inadequate treatment of type 2 diabetes, researchers should focus on studies that promote adherence to the use of medical therapies. 


\section{Research design and methods}

This research study employed the quantitative methodology. The researcher employed the crosssectional correlational design to investigate whether attitudes and intentions could predict adherence to oral antihyperglycemic regimens in African Americans. The independent or the predictive variables for this study were attitude, subjective norms, perceived behavioral control and intention toward adherence to oral antihyperglycemic regimens. Intention was used as an independent variable and as a mediating variable. The dependent or the outcome variable was adherence to oral antihyperglycemic regimens. Further, this study investigated whether the theory of planned behavior (TpB) holds for adherence to oral antihyperglycemic regimens in African Americans. In addition, the study focused more on whether the constructs of attitude and intentions toward behavior can predict adherence to oral regimens.

The cross-sectional correlational design was appropriate for this study because the study seek to establish empirical relationships between the dependent and the independent variables. In this study, the researcher purposively selected study participants to obtain the sample size of $N=115$. However, the lack of an adequate control of background factors was a limitation for making unambiguous inferences from this study results (10).

This study was conducted at Maryland General Hospital, which is an inner city hospital located in the Baltimore, Maryland. Maryland General Hospital Research Committee and the Walden University Institutional Review Board (IRB) approved this study. The IRB approval number for this study is 09-18-12-0158183. Consent was obtained from each participant after full explanation of the purpose and nature of all procedures used in the study. To protect participants' confidentiality, all identifiers such as names and phone numbers were excluded from the questionnaires.

This study consisted of individuals who identify themselves as African Americans. Researchers who have compared the sequelae of type 2 diabetes in African Americans and Caucasians have found that the disease disproportionately affect African Americans (11). Therefore, advancing research about adequate adherence to the use of oral antihyperglycemic regimens in African Americans is essential in addressing the strategies that can minimize the consequences of hyperglycemia in the African American communities.
The participants' inclusion criteria were (a) African American, (b) diagnosed with type 2 diabetes for at least one year, (c) under a care of a health care provider, (d) age 35-64 years, and (e) able to perform activities of daily living themselves. Because this study dealt with participants who exhibited medication-taking behavior under volitional control $(12,13)$, African Americans with type 2 diabetes and major psychiatric disorders such as major depression and schizophrenia were excluded from the study.

\section{Results}

\section{Descriptive statistics}

Regarding the age range of the study sample $(N=115)$, $23(20 \%)$ were aged 35-44 years, 37 (32.2\%) were aged $45-54$ years and $55(47.8 \%)$ were aged $55-64$ years. Table 1 summarizes the frequency distribution of participants' age. The average age of the participants was 50.97 years. Similarly, $10(8.8 \%)$ of the participants reported HbA1C values of less than 7, and 21 (18.3\%) reported HbA1C values of between 7 and 9 and 3 (2.6\%) reported HbA1C values of greater than 9. Of the 115 study participants, 81 (70.4\%) reported that they did not know their HbA1C values.

The adherence levels of the study participants were as follows. Of the 115 study participants, 59 (51.3\%) reported low adherence (adherence scores of less than 6 on the MMAS Scale), 33 (28.7\%) reported medium adherence (adherence scores of 6-8 on the MMAS Scale) and $23(20.0 \%)$ reported high adherence (adherence score of equal to 8 on the MMAS Scale). Table 2 summarizes the frequency distribution of participants' adherence level. The results of this study showed that adherence to the use of oral antihyperglycemic regimens remains a challenge to African Americans living with type 2 diabetes.

Table 1 Frequency distribution of participant age $(N=115)$.

\begin{tabular}{|c|c|c|c|c|}
\hline Age range & Frequency & $\%$ & Valid (\%) & Cumulative (\%) \\
\hline \multicolumn{5}{|l|}{ Valid } \\
\hline $35-44$ & 23 & 23 & 20.0 & 20.0 \\
\hline $45-54$ & 37 & 32.2 & 32.2 & 52.2 \\
\hline $55-64$ & 55 & 47.8 & 47.8 & 100 \\
\hline Total & 115 & 100.0 & 100.0 & \\
\hline
\end{tabular}

This work is licensed under a Creative Commons Attribution-NonCommercial-NoDerivs 4.0 International License. 
Table 2 Frequency distribution of participants' adherence level.

\begin{tabular}{|c|c|c|c|c|}
\hline Adherence & Frequency & $\%$ & Valid (\%) & Cumulative (\%) \\
\hline \multicolumn{5}{|l|}{ Valid } \\
\hline$<6$ & 59 & 51.3 & 51.3 & 51.3 \\
\hline 6 to $<8$ & 33 & 28.7 & 28.7 & 80.0 \\
\hline$=8$ & 23 & 20.0 & 20.0 & 100.0 \\
\hline Total & 115 & 100.0 & 100.0 & \\
\hline
\end{tabular}

\section{Hypothesis testing}

The first hypothesis that was tested in this study was related to attitudes and intentions toward adherence to the use of oral antihyperglycemic regimens.

- $H_{0} 1$ : Attitudes and intentions do not predict adherence to oral antihyperglycemic regimens in African Americans (ages 35-64) with type 2 diabetes mellitus.

- $H_{1} 1$ : Attitudes and intentions do predict adherence to oral antihyperglycemic regimens in African Americans (ages 35-64) with type 2 diabetes mellitus.

To examine this hypothesis, a hierarchical multiple regression analysis and correlation analysis were performed. The regression was significant. The results of the first multiple regressional analysis (Table 3 ) indicated that the model for perceived behavioral control, subjective norms and attitudes toward behavioral intentions of taking type 2 diabetes mellitus oral regimens predicted $37 \%$ of the variance in behavioral intentions to oral antihyperglycemic regimens. Attitudes predicted behavioral intentions to oral antihyperglycemic regimens, beta $=0.375, t(114)=4.703$, $P<0.001$, and the model explain a significant proportion of variance in behavioral intentions, $R^{2}=0.372$, $F(1,111)=21.89, P<0.001$. Table 1 shows the values for the multiple regression analysis of behavioral intentions toward attitudes, subjective norms and perceived behavioral control.

Table 3 Multiple regression analysis of behavioral intentions to the use of oral antihyperglycemic regimens toward attitudes, subjective norms and perceived behavioral control.

\begin{tabular}{|c|c|c|c|c|c|}
\hline $\begin{array}{l}\text { Independent } \\
\text { variables }\end{array}$ & $\beta$ & $\mathrm{SE}_{\mathrm{b}}$ & Beta & $\boldsymbol{t}$ & $\boldsymbol{P}$ \\
\hline PBC & 0.656 & 0.135 & 0.410 & 4.843 & $<0.001$ \\
\hline Subjective norm & 0.029 & 0.119 & 0.022 & 0.245 & 0.807 \\
\hline Attitudes & 0.419 & 0.089 & 0.375 & 4.703 & $<0.001$ \\
\hline
\end{tabular}

Note. $R^{2}=0.372, F(1,111)=21.89, P<0.001$.
Further, the beta coefficient of 0.375 of attitudes indicated that there was a direct relationship between attitudes and behavioral intentions toward the use of oral antihyperglycemic regimens in African Americans. The Pearson correlation of attitudes and intentions was 0.447 and was statistically significant at $P<0.01$. Similarly, the beta coefficient of 0.291 indicated that there was a direct relationship between behavioral intentions and adherence to oral antihyperglycemic regimens. The Pearson correlation of intentions and adherence was 0.291 and was statistically significant at $P<0.01$, indicating that there was a direct relationship between intentions and adherence.

The result of the second multiple regression analysis indicated that the model for intentions (model 1) toward adherence to the use of oral antihyperglycemic regimens predicted $8.5 \%$ of the variance in adherence to the use of oral antihyperglycemic regimens. Intentions predicted adherence to the use of oral antihyperglycemic regimens, beta $=0.291, t(114)=3.233, P=0.002$, which is less than $P<0.05$. The model explained a significant proportion of variance in adherence, $R 1^{2}=0.085, F(1,113)=10.54$, $P=0.002$, which is less than $P<0.05$. Table 4 shows the values for the multiple regression analysis of intentions, perceived behavioral control and attitudes toward adherence to the use of oral antihyperglycemic regimens.

Model 2 of the second multiple regression showed that attitudes did not predict adherence to oral antihyperglycemic regimens directly, beta $=-0.068$, $t(114)=0.689, P=0.492$, which was greater than $P<0.05$. These findings support the assumption of the TpB that attitude predicts specific or target behavior only through behavioral intention (14). The findings of this study showed that attitudes predicted adherence indirectly through behavioral intention, and intentions predicted adherence directly. Based on the findings of the multiple regressions and correlation analyses, alternative Hypothesis 1 of this study was supported. In this study,

Table 4 Multiple regression analysis for adherence to use of oral antihyperglycemic regimens toward intentions, perceived behavioral control and attitudes.

\begin{tabular}{|c|c|c|c|c|c|c|}
\hline Model & $\begin{array}{l}\text { Independent } \\
\text { variables }\end{array}$ & $\beta$ & $\mathbf{S E}_{\mathbf{b}}$ & Beta & $\boldsymbol{t}$ & $\boldsymbol{P}$ \\
\hline 1 & Intentions & 0.502 & 0.155 & 0.291 & 3.233 & 0.002 \\
\hline 2 & PBC & 0.776 & 0.276 & 0.281 & 2.813 & 0.006 \\
\hline 3 & Attitudes & -0.130 & 0.189 & -0.068 & 0.689 & 0.492 \\
\hline
\end{tabular}

This work is licensed under a Creative Commons Attribution-NonCommercial-NoDerivs 4.0 International License. 
intention was used a mediating variable between attitudes and adherence.

The second hypothesis that was tested in this study was the principle of the theory of planned behavior (TpB). According to the $\mathrm{TpB}$, behavioral intention is a function of attitudes, subjective norms and perceived behavioral control (14). According to the TpB, behavioral intentions and perceived behavioral control can predict the target behavior under investigation.

- $H_{0}$ 2: The theory of planned behavior does not hold for predicting adherence to oral antihyperglycemic regimens in African Americans (ages 35-64) with type 2 diabetes mellitus.

- $H_{1}$ 2: The theory of planned behavior holds for predicting adherence to oral antihyperglycemic regimens in African Americans (ages 35-64) with type 2 diabetes mellitus.

To examine Hypothesis 2, two multiple regressional analyses were performed and the regressions were significant. The results of the regressional analysis indicated that the first regression accounted for $37 \%$ of the variance in behavioral intentions to oral antihyperglycemic regimens. Subjective norms did not predict behavioral intentions toward adherence to oral antihyperglycemic regimens, beta $=0.022, t(114)=0.245, P=0.807$, which is greater than $P<0.05$. Perceived behavioral control predicted behavioral intentions toward adherence to the use of oral antihyperglycemic regimens, beta $=0.410$, $t(114)=4.843, P<0.001$, which was significant.

Similarly, model 2 of the second multiple regression analysis indicated that perceived behavioral control and attitudes predicted adherence toward the use of type 2 diabetes mellitus oral regimens accounted for $15 \%$ of the variance in adherence to oral antihyperglycemic regimens. From Table 3, perceived behavioral control predicted behavioral intentions toward adherence to oral antihyperglycemic regimens, beta $=0.410, t(114)=4.843$, $P<0.001$, and the model explains a significant proportion of the variance in adherence, $R^{2}=0.37$, $F(1,111)=21.89, P<0.001$.

Perceived behavioral control predicted adherence to the use of oral antihyperglycemic regimens, beta $=0.281$, $t(114)=2.813, P=0.006$, which was less than $P<0.05$, and model 2 of the second multiple regression analysis did not explain a significant portion of the variance in adherence, $\quad R 2^{2}=0.15, \quad F(1,111)=0.48, \quad P=0.48$ because of the inclusion of the variable of attitudes. Attitudes predicted behavioral intentions and not adherence. Perceived behavioral control also predicted behavioral intentions and adherence to the oral antihyperglycemic regimens.

A regression analysis of perceived behavioral control and adherence was significant. The model of perceived behavioral control and adherence accounted for 13\% of the variance in adherence. Perceived behavioral control predicted adherence, beta $=0.360, t(114)=4.098$, $P<0.001$, which was significant, and the model explained a significant portion of the variance in adherence, $R^{2}=0.13, F(1,114)=16.80, P<0.001$. Further, the Pearson correlation of perceived behavioral control and intention was 0.480 , and correlation of perceived behavioral control and adherence was 0.360 , which were statistically significant at $P<0.01$. Similarly, the Pearson correlation of subjective norms and intentions was 0.334 , and the correlation of subjective norms and adherence was 0.257 , and were significant at the $P<0.01$ level. Thus, direct relationships were observed between all the variables of the TpB model.

Subjective norms did not predict behavioral intentions in this study, beta $=0.022, \quad t(114)=0.245, \quad P=0.807$. Nevertheless, the TpB still holds for this study because attitudes and perceived behavioral control predicted behavioral intention, which predicted adherence to the use of oral antihyperglycemic regimens, and the correlations between attitudes, subjective norms and perceived behavioral control with behavioral intentions were statistically significant. Not all variables of the TpB have to be met before the theory is supported (14). In this study, the predictive variable of subjective norm was not met. Based on the analyses of the first and second multiple regressions, and the results of the correlation analysis, the alternative Hypothesis 2 was supported.

\section{Additional research findings}

Further analysis of the data showed that age, gender and $\mathrm{HbA} 1 \mathrm{C}$ values of participants did not predicted behavioral intentions to the use of oral antihyperglycemic regimens. The results of the multiple regressional analysis (Table 5) indicated that the model for age, gender and HbA1C toward behavioral intentions of type 2 diabetes oral medications accounted for $5 \%$ of the variance in behavioral intentions to oral antihyperglycemic regimens, $R^{2}=0.050, F(3,33)=0.529, P=0.666$, which was not significant. Age did not predict behavioral intentions to oral antihyperglycemic regimens, beta $=0.4073$, $t(33)=0.404, P=0.689$. Similarly, gender did not predict 
Table 5 Multiple regression analysis of behavioral intentions to the use of oral antihyperglycemic regimens toward age, gender and $\mathrm{HbA} 1 \mathrm{C}$ values.

\begin{tabular}{|c|c|c|c|c|c|}
\hline $\begin{array}{l}\text { Independent } \\
\text { variables }\end{array}$ & $\beta$ & $S_{E_{b}}$ & Beta & $t$ & $\boldsymbol{P}$ \\
\hline Age & 0.009 & 0.022 & 0.4073 & 404 & 0.689 \\
\hline Gender & -0.150 & 0.393 & -0.068 & -0.383 & 0.704 \\
\hline $\mathrm{HbA} 1 \mathrm{C}$ & -0.140 & 0.133 & -0.190 & -1.049 & 0.303 \\
\hline
\end{tabular}

Note. $R^{2}=0.050, F(3,33)=0.529, P=0.666$.

behavioral intentions, beta $=-0.068, t(33)=-0.383$, $P=0.704$. In addition, HbA1C did not predict behavioral intentions, beta $=-0.190, t(33)=-1.049, P=0.303$.

Similarly, age, gender and HbA1C values of participants did not predict adherence to the use of oral antihyperglycemic regimens. The results of the multiple regression analysis (Table 6) indicated that the model for age, gender and $\mathrm{HbA1C}$ toward adherence accounted for $12 \%$ of the variance in adherence to the use of oral antihyperglycemic regimens, $R^{2}=0.121, F(3,33)=1.382$, $P=0.267$, which was not significant. Age did not predict adherence to the use oral antihyperglycemic regimens, beta $=-0.028, t(33)=-0.161, P=0.873$. Similarly, gender did not predict adherence, beta $=-0.135, t(33)=-0.787$, $P=0.437$. HbA1C did not predict adherence, beta $=-0.331$, $t(33)=-1.900, P=0.067$.

\section{Discussion}

The findings suggest that attitudes, intentions and perceived behavioral control predict adherence to the use of oral antihyperglycemic regimens in African Americans. In addition, the findings suggest that individuals who perceive taking their type 2 diabetes medications as easy and those with a positive perception about taking their type 2 diabetes medications have high adherence to the use of oral antihyperglycemic regimens. In addition,

Table 6 Multiple regression analysis of adherence to the use of oral antihyperglycemic regimens toward age, gender and $\mathrm{HbA} 1 \mathrm{C}$ values.

\begin{tabular}{|c|c|c|c|c|c|}
\hline $\begin{array}{l}\text { Independent } \\
\text { variables }\end{array}$ & $\beta$ & $S E_{b}$ & Beta & $t$ & $\boldsymbol{P}$ \\
\hline Age & -0.007 & 0.046 & -0.028 & -0.161 & 0.873 \\
\hline Gender & -0.664 & 0.843 & -0.135 & -0.787 & 0.437 \\
\hline $\mathrm{HbA} 1 \mathrm{C}$ & -0.544 & 0.286 & -0.331 & -1.900 & 0.067 \\
\hline
\end{tabular}

Note. $R^{2}=0.121, F(3,33)=1.382, P=0.267$ participants who demonstrated favorable attitudes about taking their type 2 diabetes medications as prescribed by their clinicians had high adherence to the use of oral antihyperglycemic regimens. Attitude and perceived behavioral control were found to be strong predictors of behavioral intentions.

\section{Attitude}

The attitude of the participants was the degree to which they had favorable or unfavorable evaluations or appraisal of taking their type 2 diabetes medications as prescribed by their clinicians $(13,14)$. Attitudes predicted behavioral intentions, beta $=0.375, t(114)=4.703, P<0.001$. The multiple regression analysis for attitudes, subjective norm and perceived behavioral control accounted for $37 \%$ of the variance in behavioral intentions. This study results support the TpB facet that attitudes is a function of behavioral intentions. This finding is consistent with several studies that have shown that attitude is a strong predictor of behavioral intentions.

In this study, the alternative hypothesis, attitudes and intentions do predict adherence to oral antihyperglycemic regimens in African Americans (age 35-64 years) with type 2 diabetes, was accepted and the null hypothesis was rejected. This finding is consistent with other studies that have examined the role of attitudes and intentions in behavioral control. Gatt and Sammut (15) study suggests that positive attitude correlates directly with adherence to diabetic foot care $(r=0.36, P=0.00)$. The study by Plotnikoff and coworkers (16) examined adherence to physical activity in patients with type 2 diabetes and found that attitude was the main predictor of behavioral intention toward physical exercise.

Attitude did not predict adherence to the use of oral antihyperglycemic regimens directly, beta $=-0.068$, $t(114)=0.689, P=0.492$, which was greater than $P<0.05$. In this study, there were strong correlations between attitudes and intentions $(r=0.447, P<0.01)$ and attitudes and subjective norms $(r=0.330, P<0.01)$. The Pearson correlation between attitudes and perceived behavioral control $(r=0.159, P=0.090)$ and attitudes and adherence ( $r=0.060, P=0.522)$ was statistically non-significant. As positive attitude about taking type 2 diabetes medications increases, the perceived ease of taking the medications and perceived social pressure also increase. Participants who viewed taking their type 2 diabetes medications as pleasant, beneficial, good and nice showed high adherence to the use of medical therapies than those who This work is licensed under a Creative Commons
Attribution-NonCommercial-NoDerivs 4.0 International License. 
view taking their regimens as unpleasant, harmful, bad and awful.

\section{Intention}

The intention of participants was the perceived ease or difficulty of taking their type 2 diabetes medications as prescribed by their clinicians $(13,14)$. The TpB assumes that intention is an immediate antecedent of behavior (14). Intention in this study was employed as a mediating variable and as an independent variable. The model for intention accounted for $8.5 \%$ of the variance in adherence. Intentions predicted adherence, beta $=0.291$, $t(114)=3.233, P=0.002$. Behavioral intentions had strong correlations with attitudes $(r=0.447, P<0.01)$, subjective norms $(r=0.334, P<0.01)$, perceived behavioral control $(r=0.480, P<0.01)$ and adherence $(r=0.291, P<0.01)$. The findings suggest that participants, who planned and tried to take their type 2 diabetes medications as prescribed, adhere better to prescribed therapies.

As the social pressure to take type 2 diabetes increases, the intention to take the medications as prescribed also increases. In addition, as the degree of favorable evaluation about taking diabetes medication increases, the perceive ease of taking the medication also increases. Gatt and Sammut (15) study found a significant relationship between behavioral intentions and diabetic foot care. Thus, this study supports the usefulness of the TpB model in adherence to the use or oral antihyperglycemic regimens.

\section{Adherence}

The focus of this study was to employ the role of attitudes and intentions in predicting adherence to the use of oral antihyperglycemic regimens in African Americans. Several retrospective data analyses have reported the problem of low adherence to prescribed medical therapies (17). Bartels (17) study found that from a period of 1988 to $1998,58 \%$ patients with chronic medical conditions discontinued their drug therapy at least once.

This high level of poor adherence remains a public health problem. In this study, 59 (51.3\%) participants reported low adherence, 33 (28.7\%) reported medium adherence and 23 (20.0\%) of patients reported high adherence. These findings are similar to Morisky and coworkers' study (18) which examined the psychometric properties of adherence to antihypertensive medications.
Morisky and coworkers found that $32.1 \%$ of participants reported low adherence, $52.0 \%$ reported medium adherence and $15.9 \%$ reported high adherence. To address the high mortality and morbidity that are associated with inadequate management of type 2 diabetes, it is essential to encourage patients with diabetes to adhere to medical therapies. Individuals within the high adherence group take their regimens as prescribed by their clinicians.

Despite the low percentage of high adherence that was reported in study, some studies have reported high levels of adherence to medical therapies. Rozenfeld and coworkers' study (19), which was carried out in a managed care setting, found that $65 \%$ of patients with diabetes reported high adherence to the use of oral antihyperglycemic regimens. Similarly, in Mateo and coworkers' study (4), participants reported 50\% adequate adherence to prescribed oral antihyperglycemic regimens. In this study, participants who reported high adherence levels were more likely to report low $\mathrm{HbA} 1 \mathrm{C}$ values. In this study, the relationship between adherence and HbA1C was not statistically significant, most likely because of the small sample size $(n=33)$ of the participants that reported their $\mathrm{HbA} 1 \mathrm{C}$ values.

The demographic data analyses were performed in the additional findings section of this study. Multiple regression and correlational analyses were used to analyze gender, age, HbA1C, and adherence. Age, gender and $\mathrm{HbA1C}$ values were found to be statistically nonsignificant in this study. The sample size that was used to analyze HbA1C was small. Thus, the small sample size of 33 participants limited the results of the analysis. In this study, HbA1C did not correlate with either intention or adherence.

Several studies have found an inverse relationship between $\mathrm{HbA} 1 \mathrm{C}$ values and adherence to the use of oral antihyperglycemic agents in patients with diabetes. HillBriggs and coworkers (9) and Horswell and coworkers (20) found a strong relationship between $\mathrm{HbA1C}$ values and adherence to type 2 diabetes medications. Therefore, as the rate of adherence to the use of oral antihyperglycemic regimens increase, the $\mathrm{HbA1C}$ values decrease.

In this study, gender and age were not statistically significant, and neither gender nor age correlated with either intention or adherence to the use of oral antihyperglycemic regimens. The findings of this study are similar to those of Hill-Briggs and coworkers' study (9), which showed no correlation between gender and level of adherence to diabetic medications in African Americans. 


\section{Conclusions}

This study offers value in beginning to comprehend the role of attitudes, subjective norms, perceived behavioral control and behavioral intentions in adherence to the use of medical therapies. Understanding the interactions between these psychosocial variables and adherence is beneficial to promoting adequate adherence to the use of oral antihyperglycemic regimens.

This study is important because it focused on a population that faces great challenges of adequate adherence to medical therapies. The study sample was drawn from an urban-impoverished African Americans living with type 2 diabetes. This population is at high risk for adverse uncontrolled diabetic sequelae, and little data have been reported on medication-taking behavior in this population (9). It is essential that health care providers who work in the management of type 2 diabetes should continue to promote the role of positive attitudes, intentions and behavioral changes that can enhance the management of type 2 diabetes in African Americans and the general population at large.

The results and findings of this study include having a better understanding of how attitudes, subjective norms, perceived behavioral control and intentions can predict the use of oral antihyperglycemic regimens in African Americans with type 2 diabetes. As evident from this study, promoting positive attitudes and intentions can improve on adherence to the use of oral antihyperglycemic regimens, and thus, may have the potential to minimize, reduce or delay the negative sequelae of inadequate adherence.

The results and findings of this study are limited by the research design. The lack of an adequate control over explanations that may have accounted for these findings makes it difficult to formulate unambiguous inferences from the study result (10). The data for this study were collected from one hospital, thus limiting the generalization of the study results. Furthermore, threats to internal and external validities might have limited the results from this study.

\section{Declaration of interest}

The authors declare that there is no conflict of interest that could be perceived as prejudicing the impartiality of the research reported.

\section{Funding}

This research did not receive any specific grant from any funding agency in the public, commercial or not-for-profit sector.

\section{Author contribution statement}

Dr Emmanuel K Fai was the main researcher of the study. Dr Cheryl Anderson was the reviewer of the main manuscript and Dr Victor Ferreros was the reviewer of the methodology section of the manuscript.

\section{References}

1 Mihalko SL, Brenes GA, Farmer DF, Katula JA, Balkrishnan R \& Bowen DJ. Challenges and innovations in enhancing adherence. Controlled Clinical Trials 200425 447-457. (doi:10.1016/j. cct.2004.07.003)

2 World Health Organization. Adherence to long-term therapies: evidence for action. Retrieved March 22, 2012. Geneva, Switzerland: WHO, 2003. (available at: http://www.who.int/chp/knowledge/ publications/adherence_report/en/)

3 Haynes R, Ackloo E, Sahota N, McDonald H \& Yao X. Interventions for enhancing medication adherence. Cochrane Database of Systematic Reviews 20082 Art. No. CD000011. (doi:10.1002/14651858.CD000011.pub3)

4 Mateo JF, Gil-Guillén VF, Mateo E, Orozco D, Carbayo JA \& Merino J. Multifactorial approach and adherence to prescribed oral medications in patients with type 2 diabetes. International Journal of Clinical Practice 200660 422-428. (doi:10.1111/j.1368-5031.2006.00799.x)

5 Chiu Y-W, Chang J-M, Lin L-I, Chang P-Y, Lo W-C, Wu L-C \& Hwang S-J. Adherence to a diabetic care plan provides better glycemic control in ambulatory patients with type 2 diabetes. Kaohsiung Journal of Medical Sciences 200925 184-192. (doi:10.1016/s1607$551 \mathrm{x}(09) 70059-2)$

6 Gibson TB, Song X, Alemayehu B, Wang SS, Waddell JL, Bouchard JR $\&$ Forma F. Cost sharing, adherence, and health outcomes in patients with diabetes. American Journal of Managed Care 201016 589-600.

7 Farmer AJ, Kinmonth AL \& Sutton S. Measuring beliefs about taking hypoglycaemic medication among people with type 2 diabetes. Diabetic Medicine 200623 265-270. (doi:10.1111/j.14645491.2005.01778.x)

8 Nagelkerk J, Reick K \& Meengs L. Perceived barriers and effective strategies to diabetes self-management. Journal of Advanced Nursing 200654 151-158. (doi:10.1111/j.1365-2648.2006.03799.x)

9 Hill-Briggs F, Gary TL, Bone LR, Hill MN, Levine DM \& Brancati FL. Medication adherence and diabetes control in urban African Americans with type 2 diabetes. Health Psychology 200524 349-357. (doi:10.1037/0278-6133.24.4.349)

10 Frankfort-Nachmias C \& Nachmias D. Research Methods in the Social Sciences, 7th ed. New York, NY, USA: Worth, 2008.

11 American Diabetes Association. Living with diabetes. Retrieved March 22, 2012. Arlington, VA, USA: American Diabetes Association, 2011. (available at: http://www.diabetes.org).

12 Ajzen I. The theory of planned behavior. Organizational Behavior and Human Decision Processes 199150 179-211. (doi:10.1016/07495978(91)90020-t)

13 Ajzen I \& Fishbein M. Understanding Attitudes and Predicting Social Behavior. Englewood Cliffs, NJ, USA: Pretice-Hall, 1980.

14 Ajzen I. Attitudes, Personality, and Behavior, 2nd ed. New York, NY, USA: Open University Press, 2005.

15 Gatt S \& Sammut R. An exploratory study of predictors of selfcare behaviour in persons with type 2 diabetes. International Journal of Nursing Studies 200845 1525-1533. (doi:10.1016/j. ijnurstu.2008.02.006)

16 Plotnikoff RC, Lippke S, Courneya K, Birkett N \& Sigal R. Physical activity and diabetes: an application of the theory of planned behaviour to explain physical activity for type 1 and type 2 diabetes in an adult population sample. Psychology and Health 201025 7-23. (doi:10.1080/08870440802160984) http://www.endocrineconnections.org DOI: 10.1530/EC-16-0093 (c) 2017 The authors Published by Bioscientifica Ltd
This work is licensed under a Creative Commons Attribution-NonCommercial-NoDerivs 4.0 International License. 
17 Bartels D. Adherence to oral therapy for type 2 diabetes: opportunities for enhancing glycemic control. Journal of the American Academy of Nurse Practitioners 200416 8-16. (doi:10.1111/j.1745-7599.2004.tb00366.x)

18 Morisky DE, Ang A, Krousel-Wood M \& Ward HJ. Predictive validity of a medication adherence measure in an outpatient setting. Journal of Clinical Hypertension 200810 348-354. (doi:10.1111/j.17517176.2008.07572.x
19 Rozenfeld Y, Hunt J, Plauschinat C \& Wong K. Oral antidiabetic medication adherence and glycemic control in managed care. American Journal of Managed Care 2008 14 71-75.

20 Horswell R, Wascom C, Cerise F, Besse J \& Johnson J. Diabetes mellitus medication assistance program: relationship of effectivenes to adherence. Journal of Health Care for the Poor and Underserved 2008 19 677-686. (doi:10.1353/hpu.0.0062)

Received in final form 20 December 2016

Accepted 13 January 2017

Accepted Preprint published online 13 January 2017
This work is licensed under a Creative Commons Attribution-NonCommercial-NoDerivs 4.0 International License. 